\title{
BMJ Global Health WHO recommendations on uterotonics for postpartum haemorrhage prevention: what works, and which one?
}

\author{
Joshua P Vogel, ${ }^{\oplus 1,2}$ Myfanwy Williams, ${ }^{3}$ Ioannis Gallos, ${ }^{4}$ Fernando Althabe, ${ }^{1}$
} Olufemi T Oladapo ${ }^{1}$

\begin{abstract}
To cite: Vogel JP,
Williams M, Gallos I, et al. WHO recommendations on uterotonics for postpartum haemorrhage prevention: what works, and which one? BMJ Glob Health 2019;4:e001466. doi:10.1136/ bmjgh-2019-001466
\end{abstract}

Handling editor Seye Abimbola

Received 4 February 2019 Revised 10 March 2019 Accepted 16 March 2019

Check for updates

C Author(s) (or their employer(s)) 2019. Re-use permitted under CC BY-NC. No commercial re-use. See rights and permissions. Published by BMJ.

'UNDP/UNFPA/UNICEF/WHO/ World Bank Special Programme of Research, Development and Research Training in Human Reproduction (HRP), Department of Reproductive Health and Research, World Health Organization, Geneva, Switzerland

${ }^{2}$ Maternal and Child Health Program, Burnet Institute, Melbourne, Victoria, Australia ${ }^{3}$ Cochrane Pregnancy and Childbirth, University of Liverpool, Liverpool, United Kingdom

${ }^{4}$ Institute of Metabolism and Systems Research, University of Birmingham, Birmingham Women's Hospital Foundation Trust, Birmingham, United Kingdom

Correspondence to Dr Joshua P Vogel; vogeljo@who.int

\section{THE GLOBAL BURDEN OF POSTPARTUM HAEMORRHAGE}

Obstetric haemorrhage, especially postpartum haemorrhage $(\mathrm{PPH})$, was responsible for more than a quarter of the estimated 303 000 maternal deaths that occurred globally in 2015. ${ }^{1}$ PPH-commonly defined as a blood loss of $500 \mathrm{~mL}$ or more within 24 hours after birth-affects about $6 \%$ of all women giving birth. ${ }^{1}$ Uterine atony is the most common cause of PPH, but it can also be caused by genital tract trauma, retained placental tissue or maternal bleeding disorders. The majority of women who experience PPH have no identifiable risk factor, meaning that $\mathrm{PPH}$ prevention programmes rely on universal use of $\mathrm{PPH}$ prophylaxis for all women in the immediate postpartum period. Active management of the third stage of labour involves prophylactic administration of a uterotonic agent prior to delivery of the placenta, as well as delayed cord clamping and controlled traction of the umbilical cord (in settings where skilled birth attendants are available). ${ }^{2}$ The uterotonic is the most important component in terms of preventing PPH. ${ }^{3}{ }^{4}$ In 2012, WHO recommended oxytocin (10 IU, intravenously or intramuscularly) as the uterotonic of choice for PPH prevention at birth for all women. ${ }^{5}$

\section{RECENT INNOVATIONS IN PPH PREVENTION AND TREATMENT RESEARCH}

There have been major new developments in PPH prevention and treatment in the last decade, including technological advancements (such as inhalational oxytocin and the non-pneumatic antishock garment), new treatment strategies (such as advance distribution of prophylactic misoprostol for self-administration after birth, administration of oxytocin via Uniiject and care bundles for $\mathrm{PPH}$ management), as well as large multicountry trials of tranexamic acid for PPH treatment and a heat-stable formulation of carbetocin for PPH prevention. ${ }^{6-12}$ The increasing number of PPH prevention and management options makes it challenging for providers and health system stakeholders to choose where and how to invest limited resources in order to optimise health outcomes.

Multiple uterotonics have been evaluated for PPH prevention over the past four decades, including oxytocin receptor agonists (oxytocin and carbetocin), prostaglandin analogues (misoprostol, sulprostone, carboprost), ergot alkaloids (such as ergometrine/methylergometrine) and combinations of these (oxytocin plus ergometrine, or oxytocin plus misoprostol). Trial evidence for each of these options has been meta-analysed through multiple separate Cochrane systematic reviews that compared one uterotonic option against several other options or placebo/no treatment. However, subtle but important methodological differences have emerged between these reviews. For example, there are differences in trial eligibility criteria, review outcomes and subgroup comparisons. Some uterotonic comparisons (eg, oxytocin vs misoprostol) appear in more than one review. Cochrane review standards have evolved over time, meaning more recent reviews may have higher methodological rigour.

These problems were largely resolved by a recent Cochrane review and network meta-analysis (NMA) of 140 trials (88 947 women) that considered multiple uterotonic drug options (single or combination) and placebo or no treatment, first published in April 2018. ${ }^{13}$ A single review of multiple options meant standardisation of trial eligibility, risk of bias assessment and outcome reporting. The NMA also reported on comparisons of all options based on the full evidence network, providing estimates of effect even 
Table 1 WHO recommendations on uterotonics for $\mathrm{PPH}$ prevention

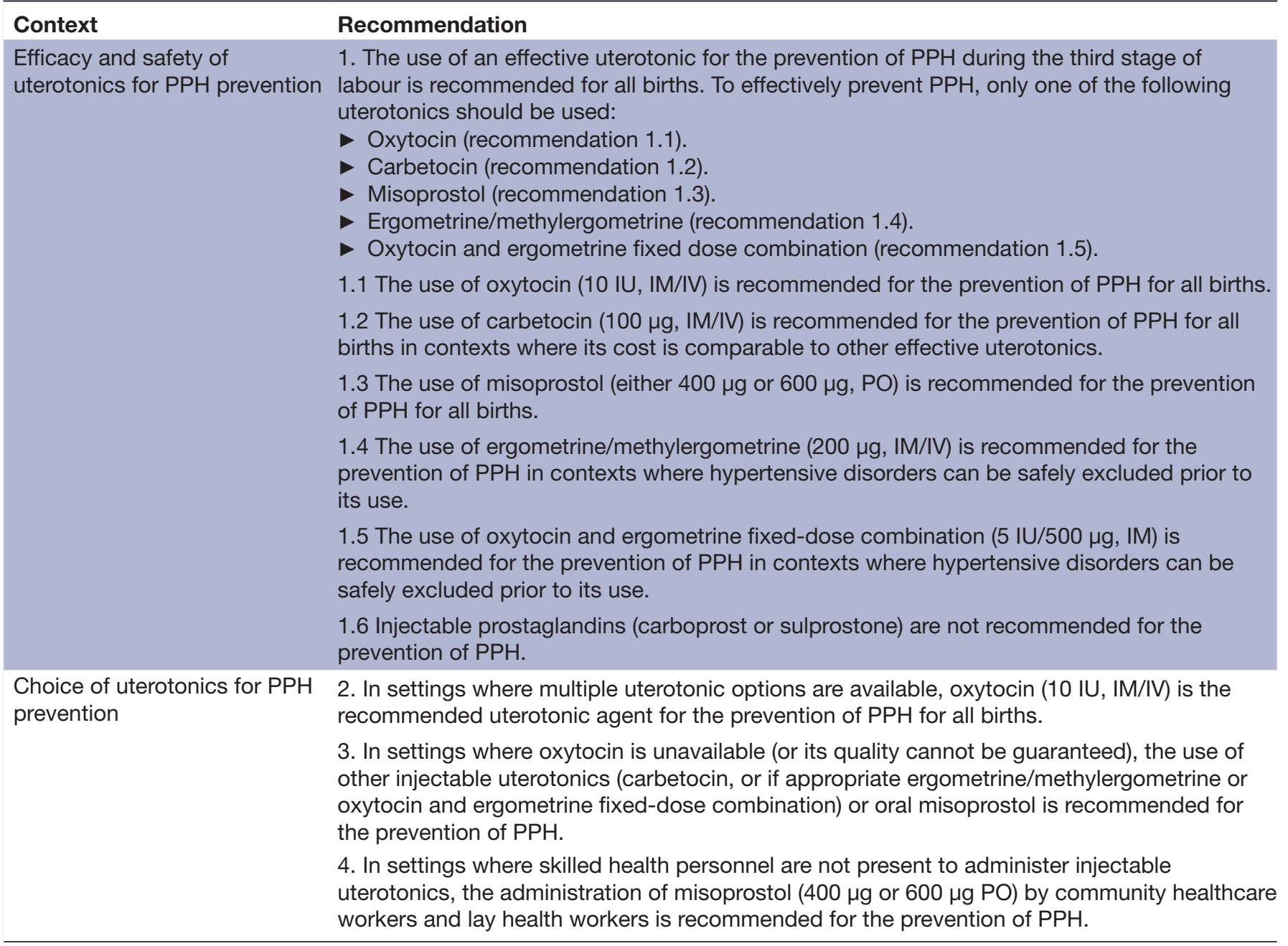

IM, intramuscular; IV, intravenous; PO, per oral; PPH, postpartum haemorrhage.

in the absence of a direct comparison ('head-to-head') trial. The NMA was closely followed by important new findings from a WHO-led, multicountry PPH prevention trial in June 2018. ${ }^{11}$ This trial randomised nearly 30000 women in 10 countries to either oxytocin (the recommended standard of care) or a heat-stable formulation of carbetocin, and found that heat-stable carbetocin was non-inferior to oxytocin for the prevention of $\mathrm{PPH}$ (defined as blood loss of at least $500 \mathrm{~mL}$ ), and the use of additional uterotonic agents. What should clinicians make of these important new findings? It was in this context that the Executive Guideline Steering Group on Maternal and Perinatal Health advised WHO to prioritise the updating of its recommendations on uterotonics for PPH prevention. ${ }^{14}$

\section{UPDATED WHO RECOMMENDATIONS ON UTEROTONICS FOR PPH PREVENTION}

In December 2018, WHO issued new recommendations on uterotonics for PPH prevention (table 1$).{ }^{15}$ Oxytocin (10 IU, intravenously or intramuscularly) remains the recommended uterotonic of choice for all births. In settings where oxytocin is unavailable (or its quality cannot be guaranteed), the use of other injectable uterotonics (carbetocin, or if appropriate ergometrine/methylergometrine or oxytocin and ergometrine fixed-dose combination) or oral misoprostol is recommended for the prevention of PPH. In those settings where skilled health personnel are not present to administer injectable uterotonics, the administration of misoprostol (400 $\mu \mathrm{g}$ or $600 \mu \mathrm{g}$ orally) by community healthcare workers and lay health workers is recommended for the prevention of PPH.

It should be noted that the uterotonic options containing ergometrine (ergometrine alone, and oxytocin-ergometrine fixed-dose combination) are context-specific recommendations, on account of the need to exclude the presence of hypertensive disorders prior to its use. This condition may limit their use in those settings where there is lack of screening for hypertensive disorders in pregnancy. WHO also made a context-specific recommendation regarding the use of carbetocin for $\mathrm{PPH}$ prevention (use carbetocin only in contexts where its cost is comparable with other effective 
uterotonics). While carbetocin is effective in preventing $\mathrm{PPH}$ (with minimal side effects), it is not available in many settings due to its high cost-in the UK, its cost is nearly 20 times that of oxytocin. ${ }^{16}$ The WHO guideline panel acknowledged that carbetocin may be cost-effective in some high-income settings (where the cost of managing PPH and its complications is high). However, they considered it uncertain whether the additional benefits of carbetocin justify the additional cost of its routine implementation at the current unit price-particularly in lower-resource settings where effective but cheaper alternatives of uterotonics are already available. The use of the heat-stable formulation of carbetocin could offer cost reductions in avoiding the cold-chain transport and storage costs associated with heat-sensitive uterotonics. The Guideline Development Group noted that the contextual nature of this recommendation may change in the future, considering the signed memorandum of understanding between $\mathrm{WHO}$ and the manufacturer of the heat-stable formulation of carbetocin to make this option available in public sector facilities of low-income and low-middle-income countries at an affordable and sustainable price (compared with the United Nations Population Fund price of oxytocin). ${ }^{11}$

The recommendations incorporated several methodological advancements compared with previous iterations. The NMA was updated (now contains 196 trials, 135559 women) to incorporate latest evidence, including the large WHO trial of heat-stable carbetocin. ${ }^{11}{ }^{13}$ This also required the application of the latest Grading of Recommendations Assessments, Development and Evaluation (GRADE) Working Group's guidance on using NMA to a WHO guideline development process. ${ }^{17} 18$ The recommendations have placed greater emphasis on a woman-centred approach, incorporating findings from a qualitative systematic review of women's perspectives and experiences of $\mathrm{PPH}$ prevention and treatment. ${ }^{19}$ This evidence proved integral to the panel's consideration of the value women place on outcomes related to blood loss after birth, the acceptability and feasibility of different uterotonics, and their possible impacts on health equity. The recommendations were developed and released rapidly (approximately 7 months after the first publication of the $\mathrm{NMA}^{20}$ ) through the innovative WHO 'living guideline' approach to maternal and perinatal health recommendations, whereby literature surveillance and systematic prioritisation guide the updating of selected high-priority recommendations on a continuous basis. ${ }^{14}$ This approach has two major advantages-it allows WHO to respond much more quickly to important changes in the evidence base (ensuring up-to-date guidance is always available), and it significantly reduces the time and resources required for updating a guideline (by focusing efforts only on those individual recommendations where an update is warranted). As uterotonics for $\mathrm{PPH}$ prevention is an active research area, this new approach will allow WHO to respond rapidly as new trial evidence continues to emerge. This can in turn translate into more rapid improvements in healthcare services and health outcomes for women.

\section{ADAPT THE WHO RECOMMENDATIONS TO NATIONAL AND LOCAL HEALTH POLICIES AND PROGRAMMES}

In light of the updated recommendations, WHO is urging international agencies and donors, as well as professional associations, clinicians and national health systems stakeholders to reassess their national health policies and protocols on PPH prevention. Stakeholders will need to consider contextual factors (such as the availability of quality-certified medicines, and the availability and training of skilled health personnel) to determine which uterotonic option should be used (see figure 1).

\section{CREATE THE NECESSARY CONDITIONS TO ENCOURAGE IMPROVEMENTS IN CLINICAL CARE}

This is an opportunity to ensure that health facilities have copies of updated, evidence-based PPH prevention and treatment protocols, job aids and decision-support tools available for immediate use in labour, delivery and postpartum areas. Any facility where women give birth requires access to a functioning supply chain, in order to ensure 24/7 availability of uterotonics for PPH prevention, as well as the necessary medicines and equipment to provide emergency obstetric care should PPH occur. Skilled heath personnel require competency-based in-service training, as well as ongoing supportive supervision to ensure their PPH prevention and management skills are up to date.

Health facilities and clinicians can also take this opportunity to review their $\mathrm{PPH}$ prevention, treatment and case fatality reduction targets, and ensure that a data-driven approach is being taken to drive improvements in care at the time of childbirth. Quality improvement activities need to engage all key stakeholders, including clinicians, programme management and quality improvement staff. Criterion-based audits of clinical records can be used to assess the effectiveness of prevention and management of PPH at a health facility level.

\section{ENSURE GOOD-QUALITY UTEROTONICS ARE AVAILABLE}

Oxytocin, ergometrine and the fixed-dose combination of oxytocin and ergometrine are heat-sensitive, requiring transport and storage at $2^{\circ} \mathrm{C}-8^{\circ} \mathrm{C}$. In settings where this cannot be guaranteed, the quality and effectiveness of these options may be limited. ${ }^{21}$ Substandard quality misoprostol has also been identified in some health facilities. ${ }^{22}$ A quality issue affecting one uterotonic may suggest that there are quality issues affecting other uterotonic options that have been procured, transported or stored under similar conditions. It is therefore advised that only quality-certified uterotonic medicines should be procured. While some manufacturer labelling may seem to indicate that oxytocin is stable at room temperature, stability may not have been tested in the much warmer conditions that 


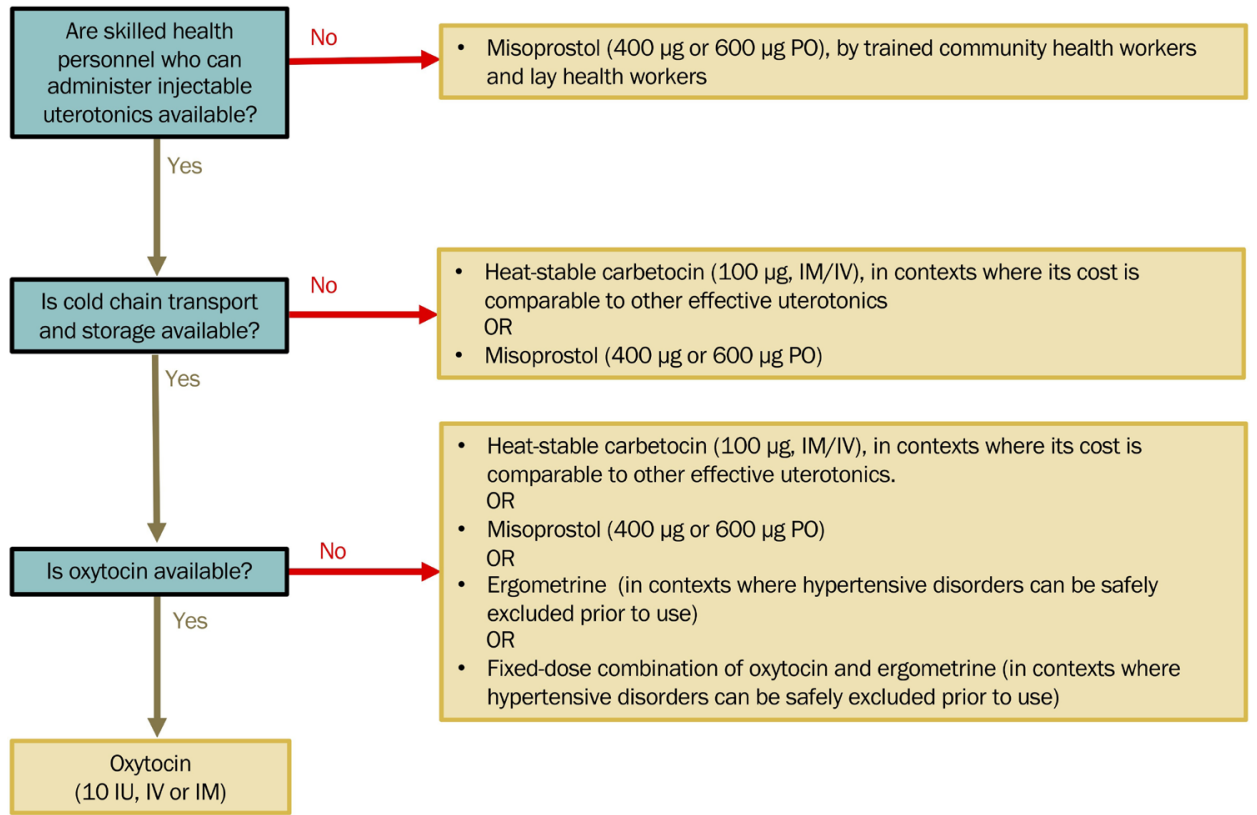

Figure 1 Contextual considerations in selecting a uterotonic for postpartum haemorrhage prevention (only quality-assured medicines should be used regardless of which uterotonic option is selected). IM, intramuscular; IV, intravenous.

are typical to many low-resource countries, and different formulations have different stability characteristics. To prevent its degradation and to safeguard its quality, oxytocin should always be stored in refrigeration, regardless of labelling.

\section{CONCLUSION}

The majority of PPH-related morbidity and mortality are preventable through the effective implementation of evidence-based guidelines. These new WHO recommendations guide skilled health personnel and other stakeholders on how best to use uterotonics to prevent PPH in women giving birth in facility or community settings in high-income, middle-income or low-income countries. To implement these recommendations, personnel need effective, quality-certified uterotonics, and the necessary training, equipment and support to ensure that all women have access to good-quality $\mathrm{PPH}$ prevention and management care at birth.

Contributors This article was conceived by JPV and OTO. All authors (JPV, MW, IG FA and OTO) contributed to the development and finalisation of the article.

Funding The authors have not declared a specific grant for this research from any funding agency in the public, commercial or not-for-profit sectors.

Competing interests None declared.

Patient consent for publication Not required.

Provenance and peer review Not commissioned; externally peer reviewed.

Data sharing statement № additional data are available.

Open access This is an open access article distributed in accordance with the Creative Commons Attribution Non Commercial (CC BY-NC 4.0) license, which permits others to distribute, remix, adapt, build upon this work non-commercially, and license their derivative works on different terms, provided the original work is properly cited, appropriate credit is given, any changes made indicated, and the use is non-commercial. See: http://creativecommons.org/licenses/by-nc/4.0/.

\section{REFERENCES}

1. Carroli G, Cuesta C, Abalos E, et al. Epidemiology of postpartum haemorrhage: a systematic review. Best Pract Res Clin Obstet Gynaecol 2008;22:999-1012.

2. Begley CM, Gyte GM, Devane D, et al. Active versus expectant management for women in the third stage of labour. Cochrane Database Syst Rev 2019;2.

3. Hofmeyr GJ, Mshweshwe NT, Gülmezoglu AM, et al. Controlled cord traction for the third stage of labour. Cochrane Database Syst Rev 2015;107

4. Gülmezoglu AM, Lumbiganon $P$, Landoulsi $S$, et al. Active management of the third stage of labour with and without controlled cord traction: a randomised, controlled, non-inferiority trial. Lancet 2012:379:1721-7.

5. World Health Organization. WHO recommendations for the prevention and treatment of postpartum haemorrhage. Geneva: World Health Organization, 2012.

6. Fernando D, Siederer S, Singh S, et al. Safety, tolerability and pharmacokinetics of single doses of oxytocin administered via an inhaled route in healthy females: randomized, single-blind, phase 1 study. EBioMedicine 2017;22:249-55.

7. Pileggi-Castro C, Nogueira-Pileggi V, Tunçalp Özge, et al. Nonpneumatic anti-shock garment for improving maternal survival following severe postpartum haemorrhage: a systematic review. Reprod Health 2015;12.

8. Oladapo OT, Fawole B, Blum J, et al. Advance misoprostol distribution for preventing and treating postpartum haemorrhage. Cochrane Database Syst Rev 2012;368.

9. Diop A, Daff B, Sow M, et al. Oxytocin via Uniject (a prefilled singleuse injection) versus oral misoprostol for prevention of postpartum haemorrhage at the community level: a cluster-randomised controlled trial. Lancet Glob Health 2016;4:e37-44.

10. Shakur H, Elbourne D, Gülmezoglu M, et al. The woman trial (world maternal antifibrinolytic trial): tranexamic acid for the treatment of postpartum haemorrhage: an international randomised, double blind placebo controlled trial. Trials 2010;11.

11. Widmer M, Piaggio G, Nguyen TMH, et al. Heat-stable carbetocin versus oxytocin to prevent hemorrhage after vaginal birth. $N$ Engl J Med 2018;379:743-52.

12. Gynaecologists ACoOa. Safe motherhood Initiative: maternal safety bundle for obstetric haemorrhage, 2015.

13. Gallos ID, Papadopoulou A, Man R, et al. Uterotonic agents for preventing postpartum haemorrhage: a network meta-analysis. Cochrane Database Syst Rev 2018:12.

14. World Health Organization. Executive guideline Steering Group for updating who maternal and perinatal health Recommendations (2017-2019), 2017. Available: http://www.who.int/reproductivehealth/ 
publications/updating-mnh-recommendations/en/: World Health Organization

15. World Health Organization. WHO recommendations: Uterotonics for the prevention of postpartum haemorrhage; 2018

16. Joint Formulary Committee. British National formulary 72 (September 2016-March 2017). London, United Kingdom, 2017.

17. Brignardello-Petersen R, Bonner A, Alexander PE, et al. Advances in the GRADE approach to rate the certainty in estimates from a network meta-analysis. J Clin Epidemiol 2018;93:36-44.

18. Puhan MA, Schünemann $\mathrm{HJ}$, Murad $\mathrm{MH}$, et al. A grade Working Group approach for rating the quality of treatment effect estimates from network meta-analysis. BMJ 2014;349:95630.

19. Downe S, Finlayson K, Oladapo O, et al. Views and experiences of women and healthcare providers on interventions for the prevention and treatment of postpartum haemorrhage: a qualitative systematic review (protocol). PROSPERO 2018.

20. Gallos ID, Williams HM, Price MJ, et al. Uterotonic agents for preventing postpartum haemorrhage: a network meta-analysis. Cochrane Database Syst Rev 2018;4.

21. World Health Organization. Survey of the quality of medicines identified by the United Nations Commission on life saving commodities for women and children. Geneva: World Health Organization, 2015.

22. Anyakora C, Oni $Y$, Ezedinachi $U$, et al. Quality medicines in maternal health: results of oxytocin, misoprostol, magnesium sulfate and calcium gluconate quality audits. BMC Pregnancy Childbirth 2018;18. 